Research Council Laboratories, Woodmansterne Road, Carshalton, Surrey. 12s. 6d.). This volume is entitled Hazards of the Animal House, and in it a number of experts discuss these hazards in general and those associated with large-scale experiments with monkeys, and those met with when dogs, cats, farm animals and birds are handled or when poliovirus is being used. Other papers discuss the precautions needed against tuberculous infection of the animal house and what virus and bacterial infections may be acquired from rats and mice. This publication is, of course, only one of others issued by the Laboratory Animals Centre. Among them is the typewritten
Bulletin issued every March and September by the International Committee on Laboratory Animals. The issue dated September 1961 continues the useful information given by former issues of this publication about the breeding, maintenance and transport of laboratory animals and other problems associated with their production and care. Appended to this issue is a list, 100 pages long, of the literature on laboratory animals of all kinds. This useful bibliography has been compiled from publications in various countries by M. A. Sabourdy and C. M. Taisne, of the Centre de Selection des Animaux de Laboratoire, Gif-sur-Yvette, France. G. LAPAGE

\title{
INDIAN STUDENTS IN BRITAIN
}

INDIAN students constitute the largest single body of overseas students at British universities. During the session 1960-61 the total number of Indian university students in Britain was 1,513 .

Although there have been previous studies of overseas students, there has been no investigation into the experiences in Britain of Indian students. A survey, described in a recent issue of Planning*, was carriod out to determine what impact has been made on the lives of a sample of Indian students who have been living in Britain for some time. The survey was carried out during the years 1959-61. Information was collected by means of questionnaires and interviews from four hundred students attending the Universities of London (200), Oxford and Cambridge (100) and Manchester and Leeds (100). The survey was confined to men as the number of Indian women students in Britain is very small.

The investigation showed that most of the students gain a new awareness and new perspectives in their genoral outlook on life. They not only meet British people, but they also meet people from various other parts of the world-Europe, Africa, America, and also people from different regions of India. From a distance, they can see India as a single nation with an identity of its own, not only politically but also culturally. They are made conscious of the backwardness and poverty that exists in their own country by contrasting it with the general higher standard of living of Western peoples, and they develop an admiration for the science, technology and organization of the West. They also develop greater admiration for some Indian values and for the Indian way of life, even though they become more critical of illiberal social practices in their country.

In the survey 88 per cent of the Indian students agree that there is no objection to borrowing science and technology from the West, but think that India should adhere to its own values: only 6 per cent disagree. Indian students want their society to change, not only economically but also socially, and they draw their inspiration partly from the Western liberal humanitarian principles of social justice and individual dignity and freedom, and partly from their own ancient traditions of idealism and spirituality. These traditions derive on one hand from those of the Upanishads and the Vedantta, with their intellectual approach, and, on the other, from those of the deeply humane saints of the Bhakti

* Planning, Vol. 27, No. 456 (13 November, 1961): Indian University Students in Britain. Pp. 281-816. (London: Political and Economic Planning, 1961.) $4 \mathrm{~s}$.
Movement, such as Kabir and Ramkrishna, with their emotional appeal.

Coming to Britain is not an isolated event, a closed and cut-off period, in the lives of the Indian students. It is fitted into and rounded off the pattern of their lives. Their experiences in Britain are influenced by their conditions back at home and by their future aspirations.

In general, middle-class Indian students have more to win and more to lose than upper-class students in the attempt to gain a foreign degree. Typically, the middle-class students are the first generation to receive an overseas education in their families, or perhaps even in their local communities. For them the experience is more magical and more exciting. Their foreign degree, as they see it, is going to bring them greater social status and prestige and raise the position of themselves and their families in the Indian social hierarchy.

Because they are financially handicapped, a delay of a few months puts a great strain on them. A few days lost through illness; a few extra months spent making up for inadequate academic preparation; a few more months over their 'schedule', inevitable because of the natural problems involved in research; a few months spent on improving work of a poor standard, poor perhaps because it is done hastily and under strain; the unexpected failure of their arranged sources of finance; the time and energy spent in some uninteresting part-time job; or bad news from horne -all these greatly disorganize and worry them.

The upper-class students have comparatively little at stake. Their families have been well established in Indian society for generations. Education overseas has become a matter of routine and is almost taken for granted. It is not an object of special ambition. Their parents and grandparents have also been educated in Britain. They add nothing of significance to the social positions of their families by adding foreign degrees, except that it is rather odd to move in a community full of 'English-returned' persons without this cachet. They are financially well-off and the expenses of their education in Britain does not put any strain on their families. A delay of a few months or a year in completing their studies does not make much difference.

Within this overall group of students there is a variety of problems. By bringing the findings of the survey before a wider public, Political and Economic Planning hopes to contribute towards a greater understanding of the difficulties confronting Indian students in Britain and also to provide a basis for administrative action. Overseas students should have 
access to detailed information about living and studying conditions before they come to Britain; they should have adequate financial support-or they will waste their energies and their opportunities; and for the early part of their stay, at least, they should be able to find accommodation in a hall of residence or hostel.
It is gratifying to be praised for the efficiency and integrity of one's public life, but the Pharisaic virtues alone are not enough. The slightness of their acquaintance with the British may have led some of the students to misjudge them, but it is depressing that so many students should have had so little contact with life beyond the university.

\title{
MEASUREMENT OF INTERPLANETARY ELECTRON DENSITY FROM THE EARTH
}

\author{
By DR M. J. BUCKINGHAM \\ School of Physics, University of Sydney
}

\begin{abstract}
$\mathrm{T}$ HE presence of free electrons in interplanetary space would influence many observable properties of the solar system as well as a number of geophysical phenomena. These influences are the basis of many estimates that have been made of the electron density and these are far from consistent with each other, ranging from less than 1 to more than 1,000 electrons per cubic centimetre.
\end{abstract}

The steady outflow of ionized gas from the Sun, the solar wind, had been supposed responsible for an electron density of $10^{3} \mathrm{~cm} .^{-3}$ at the Earth's distance from the $\operatorname{Sun}^{1}$, although more recent estimates ${ }^{2}$ have reduced this figure to $30 \mathrm{~cm}^{-3}$ During intense solar activity the density may rise to $10^{4}$ or $10^{5}$.

Recent observations of the zodiacal light by Blackwell and Ingham $^{3}$ have suggested an upper limit of $120 \mathrm{~cm} .^{-3}$ for the electron density under quiet solar conditions and a value of $300 \mathrm{~cm} .^{-3}$ during the magnetic storm of July 8, 1958.

Preliminary results of probe measurements with Explorer $X$ satellite indicate the presence of $6-20$ protons $/ \mathrm{cm} .{ }^{3}$, travelling away from the Sun with energy less than $2,300 \mathrm{eV} .^{4}$.

Since some of the estimates depend on rather indirect evidence or on dubious assumptions, it is not surprising that they disagree. A critical review of the various lines of evidence is contained in the paper by Blackwell and Ingham ${ }^{8}$.

It is the purpose of this article to point out that developments in radio astronomy now permit a direct measurement of some properties of the interplanetary electron distribution.

C. Hazard ${ }^{5}$ has recently directed attention to the fact that observation of the occultation of radio sources by the Moon enables the position and angular size of some sources to be obtained with a precision of the order of one second of arc.

An electron density of $10^{2} \mathrm{~cm} .^{-s}$ would endow interplanetary space with a refractive index, at frequencies in the neighbourhood of $100 \mathrm{Mc} / \mathrm{s}$., sufficient to cause a deviation of the order of one second of arc in the apparent position of a distant radio source. The deviation due to this refraction is proportional to the electron density and inversely to the square of the frequency.

Thus measurements of the lunar occultation of a radio source at two frequencies, one well above and one below $100 \mathrm{Mc}$./s., will produce apparent differences in position. It is likely that this difference can be measured with greater precision than the absolute position of the source, and, in favourable cases, differences in apparent position should be detectable down to a fraction of a second of arc.
It is shown here that the angle of deviation, $\delta$, produced by an electron density, $n \mathrm{~cm} .^{-s}$ (a function of position and equal to $n_{E}$ at the Earth's position) at a frequency $f \mathrm{Mc} . / \mathrm{s}$. is given by:

$$
\delta=52 \cdot 5 n_{E f^{-2}} \int \nabla_{\delta}\left(n / n_{E}\right) \mathrm{d} s, \text { seconds of arc, }
$$

where the integral is along the path from the source to the Earth and $\nabla_{\delta}$ is the component of the gradient at right angles to the path and in the direction of the deviation.

For a simple model in which the electron density is due to a radial solar wind of constant speed and in which $n_{E}$ is $10^{2} \mathrm{~cm}^{-8}$, the deviation would be about one second of are for a frequency of $50 \mathrm{Mc}$./s., when the angle between the Moon and Sun is $60^{\circ}$.

Suitable occultations are frequent enough (C. Hazard, private communication) to make these observations quite practicable. For a receiver of $150 \mathrm{ft}$. diameter perhaps fifty a year would satisfy requirements of signal to noise ratio, angular limitation of source, etc. The information obtained would be the value of the integral in equation (1), evaluated along the straight line through interplanetary space, from the Moon towards the observed source. No correction would be necessary for effects of the Earth's ionosphere or atmosphere and only changes in the interplanetary electron density could change the result for a given direction in space. Thus sufficient observations should permit a composite picture to be assembled of the steady electron density distribution in the solar system.

\section{Scattering in the Solar Corona}

In addition to the steady electron distribution in the solar system, there are transient effects due to the emission of corpuscular streams by the Sun, hydromagnetic disturbances, density fluctuations, etc. Such irregularities will cause scattering of radio waves with a consequent increase in the apparent angular size of radio sources. The scattering, like the deviation due to refraction, is inversely proportional to the square of the frequency.

The observation of lunar occultations provides a means of measuring, with a precision of the order of a second of arc, the angular size of radio sources, as well as their position ${ }^{5}$. An observed variation with frequency of the apparent size would be a measure of the fluctuations of the interplanetary electron density, just as a variation in apparent position is a measure of its gradient. 